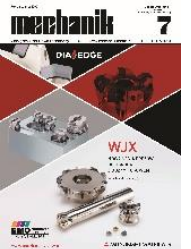

How to cite this article:

Authors: Józef Matuszek, Tomasz Seneta

Title of article: „Assessment of design manufacturability in assembly processes by modified Boothroyd \& Dewhurst DFA method"

Mechanik, No.7 (2019)

DOI: https://doi.org/10.17814/mechanik.2019.7.53

\title{
Assessment of design manufacturability in assembly processes by modified Boothroyd \& Dewhurst DFA method
}

\author{
JÓZEF MATUSZEK \\ TOMASZ SENETA*
}

Prof. dr hab. inż. Józef Matuszek, jmatuszek@ath.bielsko.pl, https://orcid.org/0000-0003-1668-6329 - Katedra Inżynierii Produkcji, Wydział Budowy Maszyn i Informatyki, Akademia Techniczno-Humanistyczna, Bielsko-Biała, Polska

Mgr inż. Tomasz Seneta, kip@ath.bielsko.pl - Katedra Inżynierii Produkcji, Wydział Budowy Maszyn i Informatyki, Akademia TechnicznoHumanistyczna, Bielsko-Biała, Polska

Paper presents the problem of evaluating manufacturability of product design. The issue was described from the point of view of course of assembly operations implementation criterion (Design for Assembly - DFA). Technological assessment of the complex product structure flow is given using Boothroyd \& Dewhurst method. Presented flow of the proceedings is illustrated by an example.

KEYWORDS: assembly processes, design manufacturability

\section{Introduction}

Determining the consequences of design decisions is critical in assessing the efficiency and effectiveness of designing production processes and systems [7]. Various methods are used to assess assembly efficiency [1-7, 9]. In the automotive industry, DFA (design for assembly) methods have gained recognition. The use of DFA methods allows for a simpler construction with fewer components $[6,7,10]$. The most common methods are Lucas DFA and Boothroyd \& Dewhurst (B\&D) DFA $[2,3,8]$. The Lucas DFA method is described in publication [7]. The study presents possibilities of applying and modifying the B\&D method.

\section{Boothroyd \& Dewhurst DFA method}

The B\&D method was developed at the end of 1970. In the following years, it was improved due to new methods and analysis techniques. The analysis is not used to develop the project, while it is used to evaluate and improve the existing structure of the designed product. Most often, it is used to assess the prototype before putting it into production [2].

The B\&D method has eight guidelines for the design of the assembly process:

- reducing the number of components (assemblies, parts),

- elimination of corrections after assembly operations,

- designing the largest possible number of product components (assemblies, parts) for self-positioning and selfassembling,

-providing adequate access and unrestricted view,

-ensuring easy assembly of components,

- minimizing the need to reorient components during assembly,

- maximizing the number of components that cannot be installed incorrectly,

- maximizing the number of components that are symmetrical (if possible) or (if not) clearly asymmetrical.

However, it should be noted that reducing the number of components of the product may lead to an increase in their complexity and increase in their manufacturing costs.

At the first stage of the assembly analysis, two characteristic parameters are determined for each part: thickness and size - figs. 1 and 2 . 

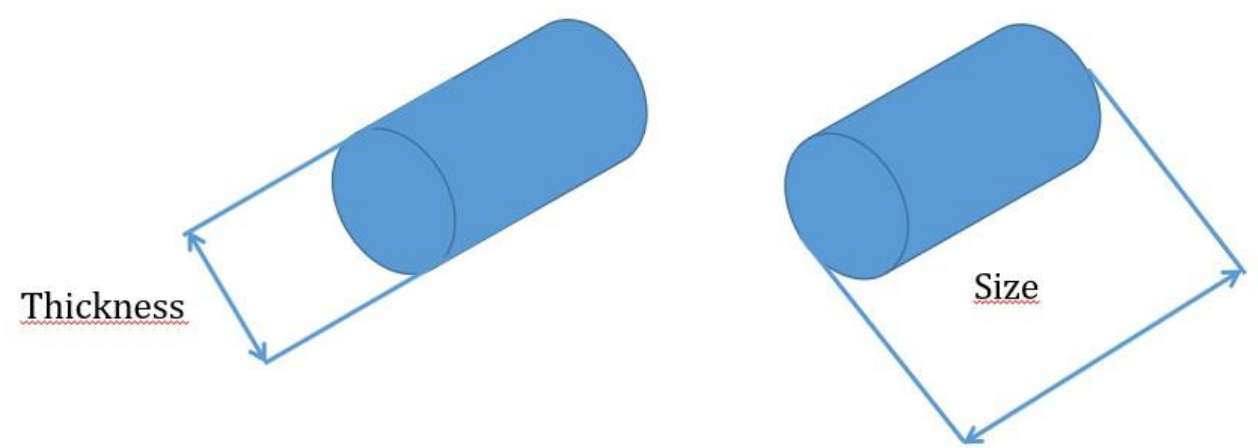

Fig. 1. Determination of thickness (diameter) and size (length) [2]

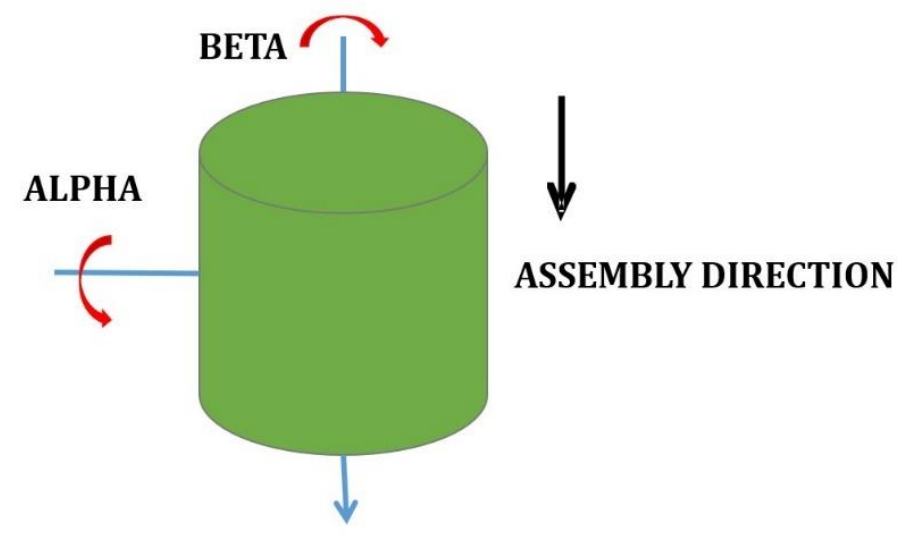

Fig. 2. Determining the ALPHA and BETA angles [2]

Thickness is the length of the shortest side of the smallest cuboid that surrounds the item. Size is the length of the longest side of the smallest cuboid that can surround the part [2].

In fig. 2, the angles BETA and ALPHA are marked. The ALPHA angle determines the symmetry of the part about the axis perpendicular to the insertion direction. BETA angle - symmetry of a part about an axis parallel to the insertion direction [2]. Based on the values of thickness and size as well as angles, indicators of handling time and setting time in assembly operations are determined. To this end, tables prepared by Boothroyd and Dewhurst are used.

Handling time indicator is determined depending on the following features and parameters of the assembly process in progress [2]:

- A component (assembly or part) is a solid or unstable part of the assembly process. An assembly is considered a part if it is assembled as a whole.

- "Required holding" means that the part being mounted is unstable when placed, inserted, or during subsequent operations and will require re-gripping and alignment or holding.

- The part is easy to assemble and determine the position if its construction form has features that facilitate assembly, e.g. by designing the chamfers on sharp edges.

- Resistance encountered while inserting parts.

- Standard tightening time includes extra time to raise the power tool, lower the screw or nut, and start the tool. When determining the time index of manipulation, it must be assessed whether the manipulation can be carried out: with one hand, one hand with an auxiliary handle, two hands, two hands with mechanical assistance. Time for placing parts is considered for three situations:

- the part is mounted but not connected,

-the part is mounted and connected,

-the part is assembled after additional operation.

For each of these situations, the embedding indicator is determined based on indicator tables. The next stage of the analysis is to check the possibility of eliminating the part. A diagram of the course of proceedings regarding the elimination of parts is shown in fig. 3 (assessment of the possibility of the occurrence of several parts in the form of one whole). 
The following course of action was developed for large-scale production. The final stage is the calculation of: the sum of the number of operations, total time of the operation, total cost of the operation, theoretical minimum number of parts and the DFMA production index:

$$
S_{\mathrm{lo}}=\Sigma O_{\mathrm{1}}
$$

where: Slo - sum of the number of assembly operations [2]; $\mathrm{Oi}-i$-th assembly operation.

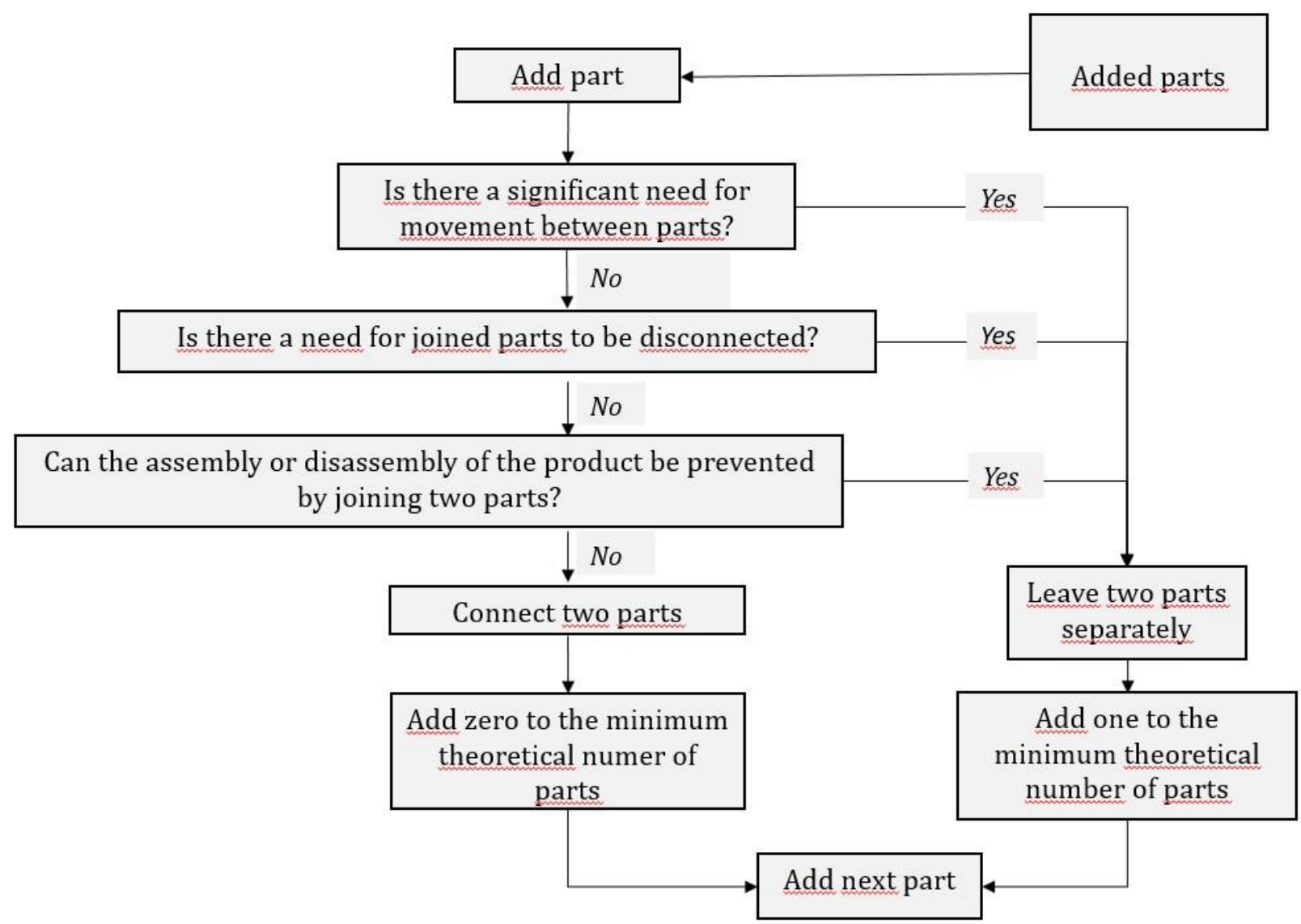

Fig. 3. Elimination scheme for B\&D DFA components [2]

$$
T_{\text {op }}=\Sigma T_{\text {mau }}+\Sigma T_{\text {mov }}
$$

where: Top - total time of assembly operations [2]; Tmau - time of the assembly operation with the $u$-th manipulation time indicator; Tmov - assembly time with $v$-th embedding time indicator.

$$
D F M A_{\mathrm{wp}}=\frac{\left(3 \cdot S_{\mathrm{lo}}\right)}{T_{\mathrm{op}}}
$$

where: DFMAwp - index of structure efficiency before assessment [2].

$$
D F M A_{\mathrm{wpo}}=\frac{\left(3 \cdot S_{\mathrm{lpo}}\right)}{T_{\mathrm{opo}}}
$$

where: DFMAwpo - structure efficiency index after analysis [2]; Slpo - sum of the number of assembly operations after the analysis; Topo - theoretical minimum assembly operation time after analysis.

An attempt was made to modify this method and its application also for serial and small-lot production. The B\&D method, due to its simple construction compared to other methods (e.g. Lucas DFA [6, 7]), according to the authors, may be susceptible to such modification. In the organization of production, the unification and standardization of product components is important, which can be determined by the index of component unification: 


$$
D F M A_{\mathrm{wUNK}}=\frac{\left(3 \cdot s_{\mathrm{UNK}}\right)}{T_{\mathrm{op}}} \quad 100 \%
$$

where: DFMAwUNK - index of structure efficiency after analysis for unified and standardized components; SUNK - sum of unified and standardized assembly components after analysis.

From the point of view of machining costs, the use of group machining plans and operations that do not require retooling work stations, the improvement of process efficiency due to the increase in production series can be determined by the index of unification of performed operations:

$$
D F M A_{\mathrm{wOG}}=\frac{\left(3 \cdot s_{\mathrm{OG}}\right)}{T_{\mathrm{OP}}} \cdot 100 \%
$$

where: $D F M A w O G$ - construction efficiency index after analyzing the construction of components enabling the implementation of group machining; $S O G$ - sum of components after analysis, possible to implement using group processing technology.

\section{Example}

According to the B\&D DFA method, the design of a single-stage gear prototype was analyzed (fig. 4).

First, the assembly process was defined, an example of which is shown in the table. $S_{\text {lo }}, T_{\text {op }}, D F M A_{\text {ip }}, D F M A_{\text {ipo }}$ values were specified for each assembled part and for each defined assembly process step

Indicator $S_{l_{0}}: S_{l_{0}}=\Sigma O_{\mathrm{l}}=113$

Indicator $T_{\mathrm{op}}: T_{\mathrm{op}}=\Sigma T_{\mathrm{mau}}+\Sigma T_{\mathrm{mov}}=683,19$

Indicator $D F M A_{\mathrm{wp}}=\frac{\left(3 \cdot s_{\mathrm{lo}}\right)}{T_{\mathrm{op}}}=3 \times 113 / 683,19=0,496(\sim 50 \%)$

In order to improve the gear assembly technology, consideration should be given to analyzing:

- the use of a new construction form (casting),

- the use of a new assembly structure - by assembling the assemblies, e.g. shaft with mounted gear, bearings, the use of tooling, visibility and easy manipulation of the value of physical loads during assembly, etc. [2].

After changing the gear structure and performing another analysis of the structure's efficiency, the following indicator values were obtained:

-after changing Swpo = 22,

-after unification Swpo = 37 including 27 unified elements,

after determining the group processing $S w p o=42$ including the number of components subject to group processing: 19 , indicator $D F M A_{\mathrm{wpo}}=\frac{\left(3 \cdot s_{\mathrm{lpo}}\right)}{T_{\mathrm{lpo}}}=3 \cdot 22 / 244,59=0,26 \sim 26 \%$

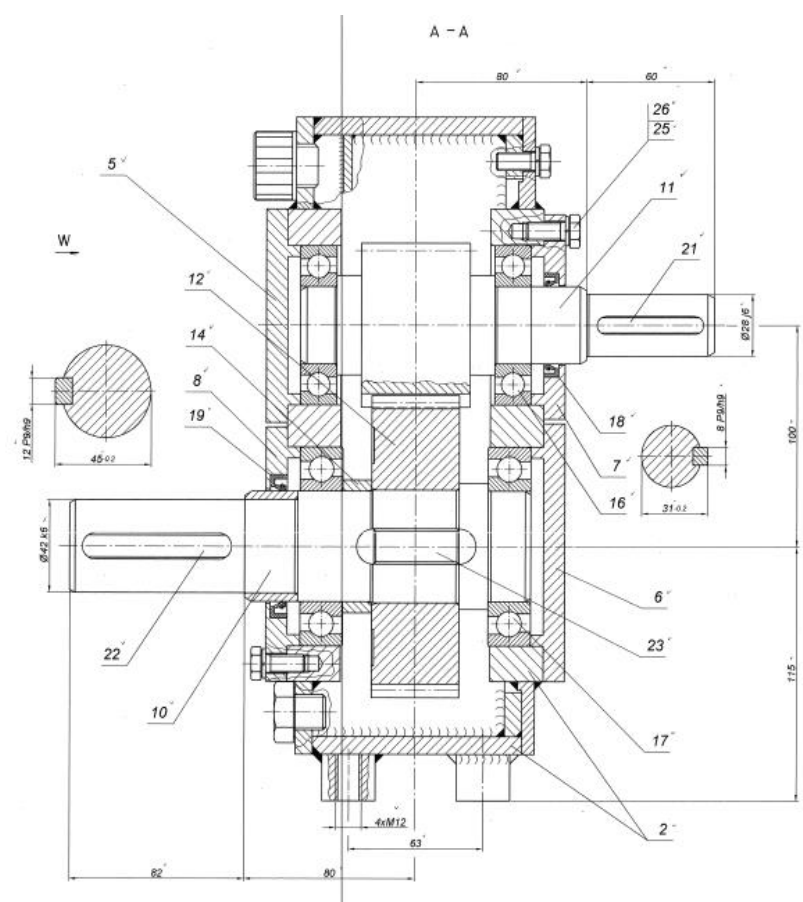

Fig. 4. Diagram of the analyzed gearbox 
Based on the given index values, other coefficients were determined for the changed design of the designed transmission:

Indicator $S_{\mathrm{UNK}}: S_{\mathrm{UNK}}=\Sigma O_{\mathrm{i}}=27$

Indicator $T_{\mathrm{UNK}}=\Sigma T_{\mathrm{mau}}+\Sigma T_{\mathrm{mov}}=372$

Indicator $D F M A_{\mathrm{wUNK}}=\frac{\left(3 \cdot S_{\mathrm{UNK}}\right)}{T_{\mathrm{UNK}}} \cdot 100 \%=3 \cdot 27 / 372=0,217(\sim 22 \%)$

Indicator $S_{O G}: S_{O G}=\Sigma O_{\mathrm{i}}=19$

Indicator $T_{\mathrm{OG}}=\Sigma T_{\mathrm{mau}}+\Sigma T_{\mathrm{mov}}=421$

Indicator $D F M A_{\mathrm{WOG}}=\frac{\left(3 \cdot s_{\mathrm{OG}}\right)}{T_{\mathrm{OG}}} \cdot 100 \%=3 \cdot 19 / 421=0,135(\sim 14 \%)$

TABLE. Results of the analysis of gear assembly manufacturability from fig. 4.

\begin{tabular}{|c|c|c|c|c|c|c|c|c|c|c|c|c|c|c|c|c|}
\hline \multicolumn{17}{|c|}{ DFMA Analysis record } \\
\hline \multicolumn{3}{|c|}{ Product data } & \multicolumn{5}{|c|}{ Components assembly details } & \multicolumn{2}{|c|}{ Manipulation } & \multicolumn{2}{|c|}{ Embedding } & \multirow{2}{*}{$\begin{array}{l}\text { Operation } \\
\text { time index }\end{array}$} & \multicolumn{4}{|c|}{$\begin{array}{l}\text { Theoretical minimum number of } \\
\text { parts/operations }\end{array}$} \\
\hline No. & Description & Initial process assumption & $\left|\begin{array}{c}\text { Number of } \\
\text { repetitions }\end{array}\right|$ & $\begin{array}{c}\text { Thickness } \\
\text { (t mm) }\end{array}$ & $\begin{array}{l}\text { Size } \\
(\mathrm{s} \mathrm{mm})\end{array}$ & $\begin{array}{c}\text { Rotation } \\
\text { Alpha } \\
\text { (degrees) }\end{array}$ & $\mid \begin{array}{c}\text { Rotation } \\
\text { Beta } \\
\text { (degrees) }\end{array}$ & Code & $\begin{array}{l}\text { Time } \\
\text { index } \\
\text { [min] }\end{array}$ & Code & $\begin{array}{l}\text { Time } \\
\text { index } \\
\text { [min] }\end{array}$ & & $\begin{array}{c}\text { Relative } \\
\text { moveme } \\
\mathrm{nt}[\mathrm{min}]\end{array}$ & $\begin{array}{c}\text { Other } \\
\text { material }\end{array}$ & $\begin{array}{c}\text { Separation } \\
\text { of parts }\end{array}$ & Do you need \\
\hline 1 & Body & download & 1 & 120 & 309 & 360 & 360 & 30 & 1.95 & 0 & 1.5 & 3.45 & $\mathrm{~N}$ & $\mathrm{~N}$ & T & 1 \\
\hline 2 & Bearing 16 & body pressing & 1 & 17 & 72 & 180 & 0 & 0 & 1.13 & 31 & 5 & 6.13 & $\mathrm{~N}$ & T & T & 1 \\
\hline 3 & Bearing 17 & body pressing & 1 & 20 & 90 & 180 & 0 & 0 & 1.13 & 31 & 5 & 6.13 & T & T & T & 1 \\
\hline 4 & Toothed shaft & bearing pressing 16 & 1 & 37 & 194 & 360 & 0 & 88 & 6.35 & 41 & 7.5 & 13.85 & T & $\mathrm{N}$ & T & 1 \\
\hline 5 & Slow speed roller & download & 1 & 28 & 216 & 360 & 360 & 30 & 1.95 & & 0 & 1.95 & T & $\mathrm{N}$ & T & 1 \\
\hline 8 & Spacer sleeve 14 & mounting on shaft assembly & 1 & 4 & 60 & 180 & 0 & 0 & 1.13 & 1 & 2.5 & 3.63 & $\mathrm{~N}$ & N & N & 0 \\
\hline 9 & Heating & gear heating up to 180 & 1 & & & & & & 0 & 99 & 12 & 12 & $\mathrm{~N}$ & $\mathrm{~N}$ & $\mathrm{~N}$ & 0 \\
\hline 10 & Roller assembly & bearing pressing 17 & 1 & 136 & 216 & 360 & 360 & 30 & 1.95 & 51 & 9 & 10.95 & T & T & T & 1 \\
\hline 11 & Cover & download & 1 & 25 & 288 & 360 & 360 & 30 & 1.95 & & 0 & 1.95 & $\mathrm{~N}$ & $\mathrm{~N}$ & $\gamma$ & 1 \\
\hline 12 & Bearing 16 & cover pressing & 1 & 17 & 72 & 180 & 0 & 0 & 1.13 & 31 & 5 & 6.13 & $\begin{array}{l}T \\
\end{array}$ & T & T & 1 \\
\hline 13 & Bearing 17 & cover pressing & 1 & 20 & 90 & 180 & 0 & 0 & 1.13 & 31 & 5 & 6.13 & T & T & T & 1 \\
\hline 18 & $\begin{array}{l}\text { Spring washer } \\
\mathrm{z} 8.2\end{array}$ & screv mounting & 10 & 4 & 14 & 180 & 0 & 5 & 18.4 & 6 & 55 & 73.4 & $\mathrm{~N}$ & N & N & 0 \\
\hline 19 & $\begin{array}{l}\text { Screw with } \\
\text { washer }\end{array}$ & screwing cover to the body & 10 & 4 & 20 & 360 & $\therefore$ & 10 & 15 & 38 & 60 & 75 & -- & N & $\mathrm{N}$ & 0 \\
\hline 22 & $\begin{array}{c}\text { Spring washer } \\
\mathrm{Z8.2}\end{array}$ & screw mounting & 4 & 4 & 14 & 180 & 0 & 5 & 7.36 & 6 & 22 & 29.36 & N & N & N & 0 \\
\hline 23 & Sealant Monolith & sealing & 1 & & & & & & 0 & 99 & 12 & 12 & N & $\mathrm{T}$ & $\mathrm{N}$ & 1 \\
\hline 24 & $\begin{array}{l}\text { Screw with } \\
\text { washer }\end{array}$ & screwing cover 5 to the body & 4 & 4 & 14 & 180 & 0 & 10 & 6 & 38 & 24 & 30 & $\mathrm{~N}$ & $\mathrm{~N}$ & $\mathrm{~N}$ & 0 \\
\hline \multicolumn{3}{|c|}{$\begin{array}{c}\text { Sum of parts/operations } \\
\text { - Before change - } 113\end{array}$} & 113 & & & & & \multicolumn{4}{|c|}{$\begin{array}{l}\text { Sum of operations times } \\
\text {-before change - } 683.19\end{array}$} & 683.19 & \multicolumn{3}{|c|}{$\begin{array}{c}\text { Theoretical minimum numer of } \\
\text { parts/operations }\end{array}$} & 22 \\
\hline
\end{tabular}

\section{Summary}

The B\&D method, by analyzing the obtained values of the parameters of assembly efficiency assessment: -allows for reducing the time, eliminating errors, reducing the process costs, taking into account, in addition to assembly, many other factors, e.g. availability of spare parts, production series, production conditions in the form of equipment types, available assembly techniques, level of automation or the scope of external cooperation orders. The method can be used for smaller production runs;

-assessment of the machinability of the structure arouses designers' creativity; The assessment of the efficiency in the form of given indicators and coefficients should be carried out by experts with extensive production experience.

\section{REFERENCES}

[1] Abdullah A., Popplewell K., Page C.J. "A review of the support to tools for the process of assembly method selection and assembly planning". International Journal of Production Research. 41, 11 (2003): 2391-2410.

[2] Boothroyd G., Dewhurst P. "Design for Assembly. A Designers Handbook", Cleveland, Ohio, USA: Penton, 1983. 
[3] Dochibhatla S.V.S., Bhattacharya M., Morkos B. "Evaluating Assembly Design Efficiency: A Comparison Between Lucas and Boothroyd-Dewhurst Methods". ASME 2017 International Design Engineering Technical Conferences and Computers and Information in Engineering Conference. V004T05A012-V004T05A012 (2017 August).

[4] James A.T., Gandhi O.P., Deshmukh S.G. "Development of methodology for the disassemblability index of automobile systems using a structural approach". Proceedings of the Institution of Mechanical Engineers. Part D: Journal of Automobile Engineering. 231, 4 (2017): 516-535.

[5] Knight W.A., Boothroyd G. "Fundamentals of metal machining and machine tools". 198 (2005). CRC Press.

[6] Matuszek J., Seneta T. „Algorytmizacja procesu wdrażania nowego produktu w warunkach wielkoseryjnej produkcji”. Mechanik. 7 (2016): 755-757.

[7] Matuszek J., Seneta T. „Ocena technologiczności konstrukcji w procesach montażu wyrobów metodą Lucas DFA". Mechanik. 7 (2017): 523-525, DOI: https://doi.org/10.17814/mechanik.2017.7.66.

[8] Pan L., Cho H.J., Park J.I. "Study on the design factors affecting the operating actions that can be used easily at the design stage". Advanced Materials Research. Trans Tech Publications. 1061 (2015): 712-715.

[9] Shetty D., Ali A. "A new design tool for DFA/DFD based on rating factors". Assembly Automation. 35, 4, (2015): 348-357.

[10] Shukor A.I.A., Adam A. "Evaluation of design efficiency using Boothroyd \& Dewhurst Method for PCB drilling machine products". International Journal of Simulation Systems, Science \& Technology. 19, 5, (2018). 